\title{
On the Convergence of Collaborative and Social Economy: A Quality Model for the Combined Effects
}

\author{
Pierina Moreno Chacón ${ }^{1, *(\mathbb{D})}$, Rejina M. Selvam ${ }^{1}\left(\mathbb{D}\right.$ and Frederic Marimon ${ }^{1,2}$ (D) \\ 1 Faculty of Economics and Management, Universitat Internacional de Catalunya, Carrer Inmaculada 22, \\ 08017 Barcelona, Spain; rmselvam@uic.es (R.M.S.); fmarimon@uic.es (F.M.) \\ 2 Research Group Quality \& Innovation for Service Excellence (QISE), Ministry of Science and Technology, \\ Paseo de la Castellana, 162, 28046 Madrid, Spain \\ * Correspondence: pierina.moreno@uic.es
}

Citation: Moreno Chacón, P.; Selvam, R.M.; Marimon, F. On the Convergence of Collaborative and Social Economy: A Quality Model for the Combined Effects. Sustainability 2021, 13, 1907. https://doi.org/ $10.3390 /$ su13041907

Academic Editors: Sajid Anwar, Roberta Arbolino and Luis Jesús Belmonte-Ureña

Received: 1 January 2021

Accepted: 5 February 2021

Published: 10 February 2021

Publisher's Note: MDPI stays neutral with regard to jurisdictional claims in published maps and institutional affiliations.

Copyright: (c) 2021 by the authors. Licensee MDPI, Basel, Switzerland. This article is an open access article distributed under the terms and conditions of the Creative Commons Attribution (CC BY) license (https:// creativecommons.org/licenses/by/ $4.0 /)$.

\begin{abstract}
This article has two aims: the first is to propose a definition for social collaborative companies that encompasses their main characteristics, and once the companies to which we refer is settled, the second aim is to propose a quality model for social collaborative companies. These companies are of a particular type based on a collaborative business model and with a social focus as part of their mission. They employ a democratic style of governance, whether or not they are cooperatives, and operate through a platform in the collaborative environment. The quality model has three main categories: management, operations, and continuous improvement in a cyclical manner to ensure continuous improvement. The findings may be interesting for academics due to the fact that it is the first attempt to provide a quality model for these social collaborative companies and provide a conceptual framework for these organizations. Additionally, some managerial implications can be evident, such as when (i) the framework functions as a management guide for excellence, (ii) a tool for benchmarking, and (iii) a tool for internal and external communication.
\end{abstract}

Keywords: collaborative economy; collaborative consumption; platform economy; sharing economy; social economy; quality

\section{Introduction}

There are many definitions of collaborative economy or collaborative consumption [1]. For this paper, collaborative economy is a business model in which activities are facilitated though collaborative platforms that create a market for the temporary use of goods or services often offered by individuals or a mediator [2]. It includes all those models of economic exchange in which there is communication between equals, either between organizations or individuals, with or without economic consideration $[3,4]$. Now, for an activity to be considered as collaborative economy, it requires the interaction of three actors: (a) a platform provider who allows the exchange, (b) a service provider, and (c) a client who seeks access to assets and consumes [4,5].

The growth of sharing models is also having an increasingly relevant impact on the revenues captured by traditional companies, and it is as an alternative to the traditional economy because of advantages such as cost reductions obtained by customers or users through the services of the collaborative economy companies [4] due to increments in efficiency through better access and use of resources [6], their great scalability potential [7], and also the client's willingness to socialize with service providers (among peers) or with other users who share the platform [8,9]. Another advantage is that the consumer is given the opportunity to enjoy a particular good without having to buy it $[7,10,11]$, which implies less risk and responsibility [5].

However, all these benefits are overshadowed by certain aspects of the collaborative economy, such as the lack of distribution of wealth among those who produce it, precarious working conditions [12], legal and tax loopholes, poor working conditions, etc. [13]. 
In light of this reality, it is necessary to know if the more successful companies can actually continue their operations without reformulating their business models towards more social perspectives [7] by conjoining both the interests of users and the general interest with the application of the principles of solidarity and responsibility [14]; that is, whether it is possible for social companies and collaborative companies to converge in a company that has the best of both sides [15] and whether this collaborative-social perspective can allow for the development of quality products and services, which permit a sustainable position to be maintained over time.

About the social economy, the main definition considered for this paper is" a group of organizations that do not belong to the public sector, have a democratic governance with equal rights and obligations of its members, and practice a particular regime of ownership and distribution of benefits, using surpluses to expand the entity and improve the services provided to its partners and society. These companies can be in these families: cooperatives, mutual, associations, and foundations" [16].

One approach to the collaborative economy and the social economy is proposed in platform cooperativism [17], but there are other collaborative companies that take the form of a social economy without being a cooperative. Perhaps then we can discover a new type of company? But how are these companies? Can a collaborative company be social? Can a collaborative company only be social if it is a cooperative? Can a social and collaborative company compete with other companies in a global market? What must workers/partners do in terms of governance to ensure long-term sustainability? How can this kind of company compete in a collaborative environment with quality products and services?

To answer these kinds of questions, the present paper's objectives are to conduct a literature review to get to know collaborative and social companies, to propose a new concept for a social collaborative company, to understand how this type of company considers these two realities, and finally to propose a quality model for the social collaborative companies validated by experts from field of both collaborative and social economy, to offer guidance to help to be more sustainable by delivering quality products and services.

\section{Convergence of the Collaborative Economy and the Social Economy}

It is necessary to compare the collaborative economy and the social economy and observe how they can complement each other and where they can be found. Starting with the collaborative economy, it has positive expectations beyond financial aspects, such as efficiency derived from the use of underutilized resources as a potential solution to income inequality [6], the possibility of citizens becoming small-scale economic agents capable of generating and exchanging value with other citizens directly $[6,17]$, greater availability of and more qualified workers, more personal connections between users [18], and many sectors that can take advantage of this new business model [7].

However, not all is good in a collaborative economy; there are some grey aspects such as concentrated investments, the existence of dominant players in some sectors [17], and the value generated not always being shared with the users who helped create it [17] (reducing marginal costs, investing, growing fast, selling, and moving forward [6], and lack of clarity regarding where taxes must be paid). In some cases, activity is not regulated by law [19], worker's rights could be threatened [20], and one wonders what would happen if massive information is captured on multiple platforms [19].

Social economy refers to the economic activities of a society seeking economic democracy associated with social utility [21]. In this context, social enterprises are aimed at the social benefit of the community or its partners, and this mission is at the center of the management [22], for whom profit is often secondary. They have management autonomy with respect to public powers, and the decision-making process is democratic (one person one vote). Adherence is voluntary, and there are equal rights and obligations among the partners [15]. There is a particular regime of ownership and distribution of benefits, with surpluses being used to expand the entity and improve the services provided to its 
members and the community in general [23]. The organization emphasizes restrictions on the private appropriation of results and on the constitution of collective patrimony [15,22].

There seems to be a meeting point between the social economy and the collaborative economy in platform cooperativism [24]. In this is found a participatory decision-making that distances the power of decisions from investors and benefits favoring a collective heritage [25]; all this is combined in the execution towards a platform [26]. There are also collaborative companies that, without being explicitly cooperative, fit within the principles of the social economy [22]. This type of company attempts to have its activity benefit many and not a few [27], reducing inequalities and contributing to the distribution of benefits to society [28]. This approach includes the collective and community aspect [29] as well as the need for trust and participation to carry out the activity and extends the scope of the collaborative economy beyond information and communication technologies, including exchanges and collaboration in the local environment [18]. It is also oriented towards reformulating concepts such as innovation and efficiency to develop mechanisms that allow for putting the person and their community at the center of the activity [24].

Companies that are collaborative and social need bear in mind that, from the collaborative point of view, it is necessary to make visible the positive consequences that they generate and make social sense of the activity that they carry out [22], and from the social side, must be able to face the difficulties related to the participative style of governance and not neglect the efficiency and sustainability of the organization [26] in addition to the achievement of social goals [12]. The Table 1 presents a comparison between social and collaborative companies with respect to two aspects:

Table 1. Comparison between social economy companies and collaborative companies.

\begin{tabular}{cll}
\hline Aspect & \multicolumn{1}{c}{ Social Economy Companies } & \multicolumn{1}{c}{ Collaborative Economy Companies } \\
\hline $\begin{array}{c}\text { The social and } \\
\text { governance spheres } \\
\text { decision-making process (away from the } \\
\text { decision-making power of those agents } \\
\text { who act as investors in the organization } \\
\text { and establish limitations in the } \\
\text { distribution of benefits in order to favors } \\
\text { a collective patrimony, an aspect that also } \\
\text { affects the organizational governance). }\end{array}$ & $\begin{array}{l}\text { Do not have it as a norm to establish the democratic } \\
\text { decision-making process, nor do they have limitations in } \\
\text { the distribution of benefits. Their activity is focused on } \\
\text { or mainly defined by the use of existing resources } \\
\text { through the previous use of these resources and their } \\
\text { the falitate the exchange of these resources. }\end{array}$ \\
$\begin{array}{c}\text { The conditions for } \\
\text { acquiring a transformative } \\
\text { or positive character }\end{array}$ & $\begin{array}{l}\text { The pursuit of the general interest and } \\
\text { the well-being of people and the } \\
\text { community are explicit. }\end{array}$ & $\begin{array}{l}\text { These companies may have this orientation towards } \\
\text { general well-being by serving a greater number of } \\
\text { consumers than the traditional economy (facilitated by } \\
\text { its high degree of scalability) as well as by the resolution } \\
\text { of social needs at a lower cost. However, these elements } \\
\text { may not be part of a company's mission but are the } \\
\text { collateral result of the activity of the organization. }\end{array}$ \\
\hline
\end{tabular}

\section{A Social Collaborative Company Definition and Its Features}

After reviewing the characteristics of both economies and considering the common and different points found in the literature review, such as social companies belonging to the private sector [24], considering the primacy of the person and the corporate purpose over capital [15], operating democratically with equal rights and obligations for partners [23], aiming to have a positive impact on society by taking into account the principles of solidarity and responsibility [30], using their surpluses to achieve objectives for their own sustainable development $[23,27]$, and requiring the interaction of three actors (a platform provider (website or app), a provider of goods or services, and those seeking access to those goods and services [4,5]), the following is proposed as a definition for the new concept of a social collaborative company (SCC):

"A social collaborative company is a private organization that is dedicated to promoting the exchange between people to sell or share products and/or services through 
a digital platform (website or app), for profit or not, whose explicit purpose with respect to its activity is to have a positive impact on the community. The company places the importance of the person before capital, with management decision-making processes being undertaken in a democratic way among its partners. It uses the outcome of economic performance (surplus) for the economic benefit of those who contribute to creating value and for the sustainable development of the company".

Based on the main features of collaborative companies such as the use of the internet, interconnection between groups of people and/or assets, access to the use of underused assets [31], the achievement of significant interactions (trust), having an inclusive and global character [12], and considering the social collaborative company definition in this paper, the following characteristics for an SCC can be established in the Table 2.

Table 2. Characteristics of social collaborative companies (SCCs).

\begin{tabular}{|c|c|}
\hline Aspect & Characteristics \\
\hline Economic and business & $\begin{array}{l}\text { - The company produces goods or services with a positive economic performance, regardless of the } \\
\text { size of the business or the turnover. } \\
\text { - It pays a reasonable salary to its workers (never below the minimum wage of the regulation) } \\
\text { - The welfare of partners, suppliers, and clients is pursued before the economic benefits. } \\
\text { - The capital of the company is private from a group of individuals from civil society or a foundation. }\end{array}$ \\
\hline Social & $\begin{array}{l}\text { - It has the explicit objective of benefitting the community (principles of solidarity and responsibility). } \\
\text { - It is a private initiative created by a group of individuals or civil society organizations. } \\
\text { - The distribution of surpluses for people and reserves of profits for the development of the activity } \\
\text { or allocation for social assets are promoted. }\end{array}$ \\
\hline Governance & $\begin{array}{l}\text { - It is formed by the partners of the company or their representatives. } \\
\text { Decisions are made based on people and their contributions of work or services based on the } \\
\text { social purpose. } \\
\text { The partners enjoy a high degree of autonomy. The distribution of shares between partners must } \\
\text { guarantee that democracy can be exercised in decision-making } \\
\text { - } \quad \text { Decision-making seeks to involve all interested parties. } \\
\text { There are equal rights and duties for partners. }\end{array}$ \\
\hline Business model & $\begin{array}{l}\text { - The economic activity is an exchange of goods or services between companies or individuals } \\
\text { through a platform (website or app). } \\
\text { The activity is lawful. } \\
\text { - It may be for profit or not. }\end{array}$ \\
\hline
\end{tabular}

It is important to clarify that for this paper, the following are not considered social collaborative companies: G2G (government to government), in which public organizations interact through the platform, even if they have an explicit objective of benefitting society [28], companies that have interrupted activity for more than a year, and those whose activity does not require exchange in legal tender, for example time banks, barters, etc.

\section{Quality in Social Collaborative Companies: A Literature Review}

In collaborative social companies, there are at least three actors, the service provider, the platform, and the client [5], and quality depends simultaneously on them and their interaction [2]. None of the actors can be neglected, even more so in social collaborative companies, since these social companies operate in the context of capitalism [13], which must be competitive to be sustainable and to guarantee their long-term viability [32], for which quality is considered a key aspect [33].

Therefore, in this field, we need to ask the following questions: How can standards be applied in a SCC? How can the quality of a product or service of an SCC be measured? What is the impact of the platform on customer satisfaction? To try to find an answer to these issues, a literature review has been carried out on the most relevant quality models 
and those related to the collaborative economy in order to present a quality model that serves to guide SCCs in their quest for competitiveness, sustainability, and survival.

\subsection{Quality Models in Social Activities}

The most important quality model related to quality in social activities is proposed by the European Quality of Social Services (EQUASS). EQUASS aims to improve the social services sector by involving providers in quality, continuous improvement, and learning and development to guarantee service users the quality of these throughout Europe [34]. This certification was adopted by more than 650 companies in different European countries from 2012 to 2015 [35], with a satisfaction rate of around 85\% among the companies that have been certified [36]. The EQUASS 2018 system comprises 10 quality principles: leadership, staff, rights, ethics, partnerships, participation, continuous improvement, results orientation, being person-centered, and comprehensiveness [37].

\subsection{Quality Service Model}

The main reference for quality service is the Parasuraman model [38], which is still consulted today. The model proposes a service quality model based on an expectationconfirmation paradigm, which suggests that consumers perceive quality in terms of their perceptions. Thus, when customer expectations are greater than their perceptions of the delivery received, service quality is considered low. When perceptions exceed expectations, the quality of service is high. This model presents five "gaps" between customer expectation and service delivery that might have a negative effect on perceived service quality: knowledge gap, design gap, performance gap, communication gap, and customer gap. In addition to considering expectation-confirmation, other proposals define quality as an aggregate of technical quality that measures the results of the service (the what) and the functional quality of the processes (how the service is made) [39].

\subsection{Quality and Excellence Model of European Foundation Quality Management (EFQM)}

EFQM is a globally recognized model of quality and excellence that aims to help organizations achieve success by identifying and understanding existing gaps to find the best solutions available. This model has had variations over time, and although it retains its original principles in the most recent version of the year 2019, it is based on the importance of the primacy of the customer; the need to take a long-term, stakeholder-centric view; and understanding the cause-and-effect linkages between why an organization does something, how it does it, and what it achieves as a consequence of its actions [40].

The structure of the EFQM model answers three questions (blocks): direction, results, and execution. Direction: this block prepares the way for the organization to be a leader in its ecosystem and be well positioned to carry out its future. Results: the direction block sets the direction for the company, but then the organization needs to execute the strategy effectively and efficiently. Execution: this is what the company achieves because of the direction and results blocks, including a forecast for the future.

\subsection{Business Models in Collaborative Economy}

The quality management model for collaborative companies has been presented to evaluate the quality of the services provided by collaborative companies [41]. It is an adaptation [41] of the Gap service quality model presented by Parasuraman et al. (1985). The model is reformulated in a cyclical model to consider that gaps can exist every time the service is repeated. Additionally, if the service is repeated, it can be revised and improved over time by introducing best practices according Deming's cycle of PDCA (plan-do-checkact or plan-do-check-adjust) [41-44], and this proposal included an additional gap to take into account external and internal communication and later closed the gap between quality of service provided and customer perception. Additionally, there is another adaptation to be introduced in order to adjust the model for quality management in in collaborative consumption services. It includes another cycle to consider the differences between the 
expectations and perceptions of the client vs. the platforms. This second cycle includes six new gaps; these two different cycles overlap in time, requiring simultaneous analysis. Although these two cycles have been represented concentrically, this does not imply that there is dependency between both cycles.

Another business model to consider is the sharing business model compass [6]. In this proposal, the model affirms that current models cannot account for the complexity underlying sharing business value propositions, nor can it offer a way forward for those interested in crafting models for the creation and delivery of sharing-based value. The compass specifies six distinct dimensions, which in combination allow for expanding the scope of business model possibilities for sharing start-ups and corporate ventures. These dimensions are platform type (actors being connected in the two-sided market by the intermediary), technology, transaction types (on the platform), business approach (profit-driven, hybrid with explicit social or environmental objectives, and mission-driven, where the primary goal is social and/or environmental benefits), shared resources (optimizing of new resources, finding a new home for used resources and the optimization of underutilized resources), and the governance model (with respect to decision-making and value exchange). Instead, the compass offers a range of 18 variables to choose from and combine across the six dimensions, providing orientation and supporting the profiling of sharing business. Regarding the valuation of collaborative economy and collaborative social economy companies, this model has four dimensions of these models, which are at the "core" of the model (platform type, transaction types, business approach, and governance model) for considering the differences between models that are market-oriented and models that are closer to collaborative manners. In this way, the authors propose that it is possible to consider the realities of cooperatives and corporations.

\subsection{Some Considerations about the Platform and Governance}

Other studies that are not about quality models for collaborative companies or for collaborative social companies also provided useful information when making the model presented in this document. For example, the European Agenda for Sharing Economy [45] proposes the importance of the platform considering three key criteria: price, key contractual conditions, and key asset ownership. When these three criteria are met, there are clear indications that the collaborative platform exercises significant influence or control over the underlying service provider, which may in turn indicate that it should also be considered as providing the underlying service. This also forces us to consider that if the level of influence of the platform is high, it must respond to the client for a service/product quality that does not meet their expectations [29].

Regarding governance for social collaborative companies, for good management it is necessary to take four categories of effects derived from the governance mechanisms established by a cooperative platform into account [21]: redirecting capitalism: limitation of wages, restriction of capital investments, distribution of benefits, and search for alternative sources of financing; engaging the community: commitment to open community access, access to conflict scenarios, collective decision-making, and consensus building; democratic participation: democratic values, one member one vote, responsibility and accountability, and development of self-management strategies; and mandatory transparency: publishing information about company activities, publishing the use of user data, and allowing members to monitor and supervise.

\section{Quality Model for Social Collaborative Companies (SCCs): A Proposal}

The quality model for an SCC aims to present a guide so that it can offer products and services with an adequate level of quality so that their clients can grow [46] and the company can be sustainable over time [47]. This model is a theoretical exercise based on the literature review and in-depth insights provided by experts from the field. Expert rationale was added to ensure the quality of our analysis and to answer our objectives. We accomplished this step using validation from five experts included in the study using 
purposive sampling technique, who interpret the meaning and context to the findings from the literature review included in the formation of the quality model.

The SCC has just been defined in this paper, but it is already possible to find some examples of it operating in the market; in fact, some companies are showing growth and resilience [21], and could be taking advantage of a quality model to understand themselves better, given the complexity of the sharing economy for companies with a social mission [30] and a democratic governance.

This quality model aspires to provide useful insights for all stakeholders, not only with respect to understanding, but also with respect to finding solutions oriented towards the general strategy and its future. The quality model is a guide that can be used together with other existing models. It is desired that SCCs apply it in the future, reflecting on other dimensions that can be developed or different aspects that can be improved or adapting certain aspects that are very particular to their activity.

Considering that quality is about providing products and services in accordance with customers' expectations [41], customers of the sharing economy have their own particularities. Currently, individuals create ideas and entertainment in addition to consuming them [7]. Consumers often become prosumers (this is a new work endeavouring towards accomplishing the conceptual mix of the terms: producer and consumer) [48]; that is, they have gone from being isolated individuals to being connected. When they make decisions, they no longer do so out of ignorance, but are informed [5]. They are no longer passive, but are an active source of information feedback for companies [47].

With this type of customer, the objective of collaborative quality is focused on satisfying the customer in a functional, emotional, and holistic way, since one of the consequences of globalization has been the generation of an interconnected economy, which is not synonymous with equitable. This has led to a change in the profile of the consumer, who has become more aware and sensitive not only to their immediate environment, but also to the global one [21]. However, how can the SCC have presented all the complexity? What is the importance of the platform? What is the importance of the product or service that it offers? What is the relationship between them?

The quality model proposes an easy answer to this type of question without losing sight of the fact that in SCCs the decision-making processes are participatory and more complex, the products and services needs to be competitive, but also remain engaged with their social mission [49], and all this without losing sight of having viable financial results. The idea is that social enterprises generate wealth, are competitive, and can survive with good results in the current conditions that are so difficult [24].

The literature review of the models allows us to consider the most important aspects that have been considered for the quality model, as can be seen in the Table 3:

Table 3. Aspects to Consider for the Quality Model for Social Collaborative Companies.

\begin{tabular}{|c|c|}
\hline Model & Aspects \\
\hline EQUASS & $\begin{array}{l}\text { Leadership: Demonstrate governance, leadership, and social responsibility. They set ambitious } \\
\text { organizational and service goals and promote best practices. They are committed to continuous } \\
\text { learning and innovation. } \\
\text { Results orientation: Achieve the expected results, benefits, and best value for the customers and } \\
\text { relevant stakeholders (including investors). The impacts of services are measured and monitored and } \\
\text { are an important element of continuous improvement, transparency, and accountability processes. } \\
\text { Continuous improvement: Committed to continuous improvement of their services and results. } \\
\text { They are proactive in meeting the future needs of customers and stakeholders, using information } \\
\text { based on objective data to develop and improve. }\end{array}$ \\
\hline Quality service model & $\begin{array}{l}\text { The key aspect of this model is its proposal that the quality is related to the relationship between } \\
\text { customers' needs, service expected, and service perceived, and that all GAPs can occur if the service } \\
\text { is not managed in appropriate way and consider what the company must do to deliver a service } \\
\text { according to the customers' expectations, taking into account key aspect such as the specifications of } \\
\text { the services, external communications, and service design from pre-contact to post-contact with } \\
\text { the customers. }\end{array}$ \\
\hline
\end{tabular}


Table 3. Cont.

\begin{tabular}{|c|c|}
\hline Model & Aspects \\
\hline $\begin{array}{c}\text { Quality and } \\
\text { excellence model }\end{array}$ & $\begin{array}{l}\text { Presents three blocks: direction (prepares the way for the organization to be a leader in its ecosystem } \\
\text { and be well positioned to carry out its future), results (sets the direction for the organization, but then } \\
\text { the organization needs to execute the strategy effectively and efficiently), and execution (what the } \\
\text { organization achieves because of the direction and results blocks, including a forecast for the future). } \\
\text { Inside these blocks, there are several aspects to be considered: The vision of future and the } \\
\text { importance of the strategy includes the purpose, organizational culture, and leadership. On the other } \\
\text { hand, the remark needs to involve stakeholders, create sustainable value, manage the operation and } \\
\text { transformation, and finally invite consideration of the perception of interest groups and the strategic } \\
\text { and operational performance. }\end{array}$ \\
\hline $\begin{array}{l}\text { Quality service model for } \\
\text { collaborative companies }\end{array}$ & $\begin{array}{l}\text { Model to evaluate the quality in services provided by collaborative companies, based on the GAP } \\
\text { model from Parasuraman et al. (1985). The most relevant aspect considered for the models was the } \\
\text { cyclical proposal, which considers that gaps can exist every time the service is repeated. This could } \\
\text { be interpreted as the dynamic being continuous, and all the actions or continuous improvement } \\
\text { affecting the general results of the company, according to Deming's cycle of PDCA (Deming, 1993). } \\
\text { Also relevant is the service quality gap, such as the closing idea to explain the differences between } \\
\text { expected service and perceived service, based on the previous five GAPs. }\end{array}$ \\
\hline $\begin{array}{l}\text { Sharing Business } \\
\text { Model Compass }\end{array}$ & $\begin{array}{l}\text { The compass specifies six distinct dimensions; the most relevant of them are the following: platform } \\
\text { type: an expression of the type of actors being connected in the two-sided market by the } \\
\text { intermediary; technology: the reliance on digital technologies for facilitating discovery and exchange } \\
\text { on the platform; business approach: considered a business approach to reflect the financial and } \\
\text { impact objectives of the company. The business approach taken by sharing economy start-ups ranges } \\
\text { from profit-driven; hybrid, where the firm has explicit social or environmental objectives; } \\
\text { and mission-driven, where the primary goal is a social and/or environmental benefit. Governance } \\
\text { model: the approach adopted by the platform with respect to decision-making and value exchange. } \\
\text { Using the compass, all its dimensions could be adapted to collaborative companies inside the regular } \\
\text { economy (platform capitalism) and to more social companies (platform cooperativism). }\end{array}$ \\
\hline
\end{tabular}

After having identified the aspects to consider and from the expert validation, three dimensions of the quality model are proposed: management, operations, and continuous improvement. An uninterrupted cyclical relationship arises among them, in which each of these dimensions mutually influence each other; the aim is to combine the management with an excellent operation and keep improving (see Figure 1).
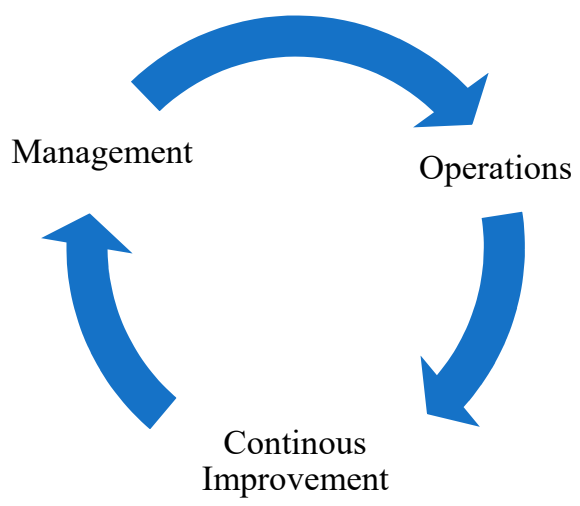

Figure 1. Dimensions of the quality model for social collaborative companies.

In order to explain the relationship between each model reviewed and the dimensions proposed before in this quality model for social collaborative companies, it is presented in Table 4: 
Table 4. Relationship between business and quality models considered and the dimensions of the quality model for social collaborative companies.

\begin{tabular}{|c|c|}
\hline $\begin{array}{l}\text { Dimension of the Quality } \\
\text { Model Proposal }\end{array}$ & Relationship with the Models Considered in Key Aspects \\
\hline Management & $\begin{array}{l}\text { - } \quad \text { EQUASS: Leadership (governance, leadership, and social responsibility). } \\
\text { EFQM: direction block (way for the organisation to be a leader in its ecosystem and be } \\
\text { well positioned). } \\
\text { - Sharing Business Model Compass: Business approach and governance dimension }\end{array}$ \\
\hline Operations & $\begin{array}{l}\text { EQUASS: Results orientation } \\
\text { - Quality service model: The GAPs between customers' needs, service expected, and service } \\
\text { perceived can occur if the service is not managed in appropriate way. } \\
\text { EFQM: results block (the organisation needs to execute the strategy effectively and efficiently), } \\
\text { and execution block (excellence in strategic and operational performance) } \\
\text { - Sharing Business Model Compass: platform and technology dimension }\end{array}$ \\
\hline Continuous improvement & $\begin{array}{l}\text { EFQM: Committed to continuous improvement of their services and results. } \\
\text { Quality service model for collaborative companies: cyclical proposal where all actions or } \\
\text { continuous improvement affect the general results }\end{array}$ \\
\hline
\end{tabular}

\subsection{Management}

Management is where it all begins; it is the world of ideas, where the directors think about what they want to do, why this value offer is socially collaborative, and what makes sense for this SCC - in short, what needs to be done to deliver a sustainable value proposal for the stakeholders inside the collaborative economy environment. The management dimension is composed of four subcategories: strategy, leadership, social management, and governance. These subcategories work together and influence each other. This can be represented in a circle such as (see Figure 2):

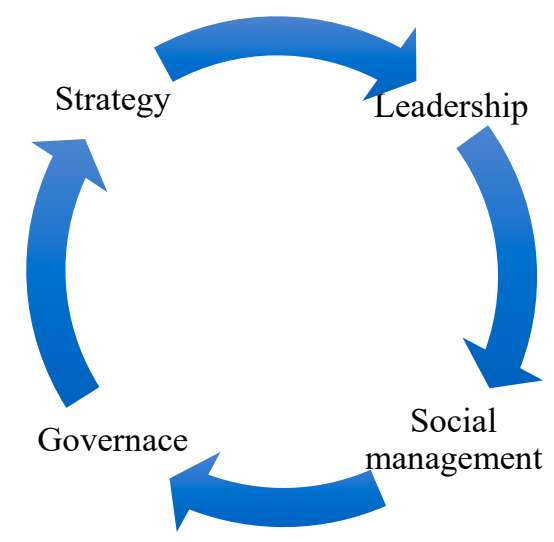

Figure 2. Subcategories in management dimension.

\subsubsection{Strategy}

For this quality model, the purpose of the definition is to answer the following questions: why is it important to work on this? How does is it intend to fulfil it? How can this purpose be kept over time? It is recommended that the company have a present mission and future vision and be very clear about what it wants to achieve in the short and long term. The purpose and vision support the strategy.

On the strategic level, it is necessary that the SCC have an understanding about the stakeholders' needs (leadership, social management, and governance). Finally, the strategy should have a concrete implementation plan, which explains how the mission and vision will be achieved. 


\subsubsection{Leadership}

In an SCC, leadership takes on a sensitive nature; its social mission should be accompanied by behaviors that are aligned with it at all levels of the organization. In leadership, it is important to highlight the need to develop a culture based on co-creation [40] (like teamwork), where a win-win paradigm is part of it. The main objective of the leadership role is to inspire appropriate behaviors, redirect deviations, and give credibility to stakeholders on the alignment of the organizational culture with the company's social mission.

The leadership role defines the values, including the social mission inside the collaboration and participation environment; creates the conditions for realizing its activities according these values; enables creativity, innovation, diversity, solidarity, etc.; and finally, promotes engagement to fulfil the mission, vision, and strategy.

\subsubsection{Social Management}

A social mission is not enough. On the social edge, the collaborative social enterprise partly has doing well as its reason for being a positive influence in society. It is part of the "why"; therefore, a company need to consider its relationship with the society to which it belongs or which it wants to influence.

Management should include a deep analysis of the context, considering everything that happens around it, such as the environment, the relationship with the public administration, knowing who the stakeholders are, the needs and expectations of its customers, leadership, relationship with its suppliers, communications, perception of the values of its brand, etc. When the context is clear, it can give support to the strategy.

\subsubsection{Governance}

The most critical voices of the collaborative economy point out that part of the problem is that power and wealth are concentrated in the hands of few people, so the benefits of scalability offered by platforms are overshadowed by something that resembles aggressive capitalist practices. One answer to this is found in platform cooperativism, or more broadly in SCCs as defined in this paper.

These companies have a democratic style of government, where one person equals one vote. However, it is essential that companies can handle the complexity that this form of decision-making involves, with its advantages and disadvantages. The main advantages are that greater involvement of workers is achieved, their decisions matter, and they learn from general aspects of the business; in short, what "happens" in the company depends on them, and they are not passive bystanders. However, this governance model faces difficulties such as needing to spend more time and effort in the search for consensus and the apparent contradiction that the worker acts as "boss" at the same time.

Added to this, the SCC needs to guarantee transparency in the information for decision-making; it should have all the concrete mechanisms necessary to obtain consensus, along with appropriate leadership and control management that fosters participation and collaboration framed in solid values and the adequate integration of the mission and vision in each of the decisions that are made.

\subsection{Operations}

This dimension refers to all the processes that are necessary for a person to enjoy the products or services offered by the platform with an adequate quality [50], necessary for current and future success.

For the operations, the quality model considers the importance of all the actors (provider, customer, and platform) in the quality perceived by the client [51]. An SCC may have the best product or service, but if it does not have good quality on its platform, the "total" quality perceived by the client will not be satisfactory. The same is true the other way around; a company can have the best platform, but if the product or service does not have the required quality, it will not leave the customer satisfied either. For this reason, all of these actors must work towards operative excellence (see Figure 3). 


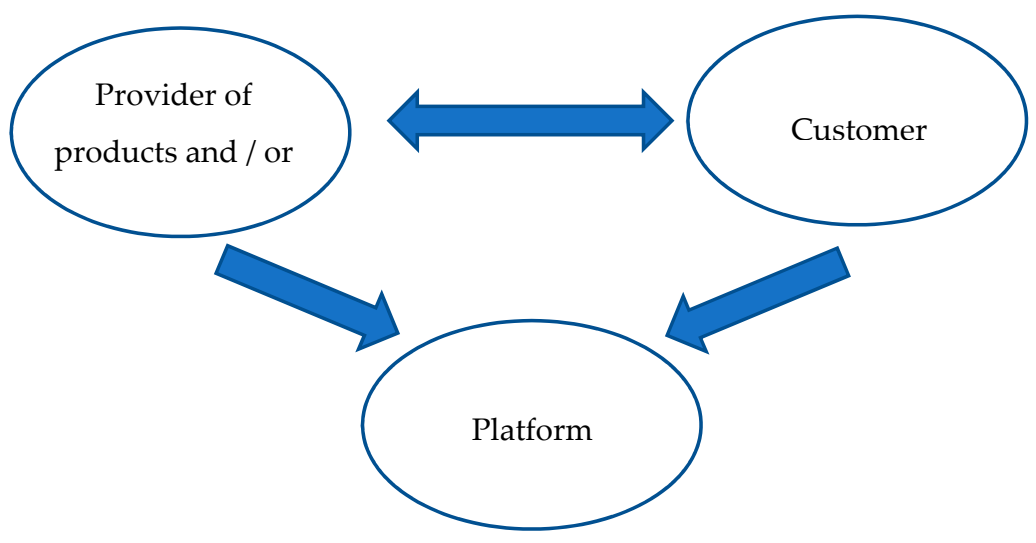

Figure 3. Subcategories in operations dimension.

\subsubsection{Provider of Products and/or Service}

In collaborative business models, anyone can be a provider of a certain product and service. Now, taking into account that the quality perceived by the client is higher when their expectations and their perception of the product or service received are aligned, it is important that the SCC applies professional tools for development, evaluation, and measurement of its performance. Another very important aspect about providers is that the company assumes the responsibility of defining in detail and efficiently communicating the needs and expectations of the client regarding the product and service and the platform that acts as an intermediary. This quality model does not include the type of contract, agreements, or terms and conditions that apply to each part, but only highlights the essential parts to improve the quality of products and services delivered for SCC.

The company needs to develop requirements for choosing providers and carry out an evaluation to determine their "suitability". It should also develop actions to advance suitability that do not meet the requirements and complement them to develop and improve their performance. A provider must have clear aspects such as operational capacity, cost structure, customer requirements, process indicators, platform operation, on time delivery, ethical code, etc.

On the other hand, it is necessary to evaluate the performance of providers, considering the comments and to go beyond the observation of customer comments on platforms. There may be dissatisfied customers who does not write a review. Additionally, when a customer writes a negative comment, negative perception of the quality of the product or service delivered is already in an individual's mind; therefore, it is not possible to carry out preventive actions.

\subsubsection{Customers}

Even before defining the strategic aspects (value proposition, purpose, vision, etc.), the SCC need to know what its client wants, what it does not like, what it likes, etc. Knowing customer requirements and expectations is a key factor for sustainability and for designing operational processes capable of giving responses to customers. It should be borne in mind that the consumer is very informed and has great power; at the click of a button, a consumer can go to another platform and leave a very bad recommendation on the platform.

For the other side, do clients know what they can expect regarding quality of the products or services they obtain through an SCC? For the answer to always be affirmative, the SCC should ensure that the customer knows that they can expect the product and/or service that they have purchased, like an in-person experience, and what they should expect from the suppliers and the platform separately. This is important for the customer to have expectations that are in line with reality and for the SCC to assess its ability to adjust to certain customer requirements. 
In addition to the specific requirements of the products and/or services that clients obtain through the platform, it is necessary to identify good practices that will generate an approach to customers, for example: communication strategy, brand image, the media where messages are transmitted, the availability and transparency in the handling of data, etc.

\subsubsection{Platform}

In this quality model, the platform is considered part of the operational management. It is a facilitator of the delivery of products or services that correspond to the company's value proposition.

As in the case of the supplier, it is recommended for the SCC to invest part of its efforts in knowing the expectations and needs of the client regarding the operation of the platform so that its operations are adequate and do not interfere with the perception of the quality of the products or services delivered.

In the case in which the company has an external platform provider, it is very important for the company to have a very close relationship with it, which includes adequate control over this subcontracted process, which can be a legal agreement about the ability to make changes, data processing, and other commitments about the ability to respond to changes in the organization to adapt to the products or services provided. If the platform is developed and managed internally, it must be considered a key actor, and the organization should be able to control that the platform has adequate capacity and efficient operations.

In any case, the company needs to ensure that it adequately communicates the client's requirements regarding the platform and that the platform is really in charge of facilitating contact between supplier and client and also facilitating the delivery of products and services in accordance with what is established.

The platform is considered an added service to the product or service, but in addition to this, it is a great provider of data that must be analyzed for continuous improvement.

Finally, one cannot lose sight of the fact that any change in the provider's or platform's operations may affect the quality of the products or services; therefore, it is necessary for the organization to constantly analyze these changes and ensure that actions are taken so that the perception of customer quality is not negatively affected.

\subsection{Continuous Improvement}

Continuous improvement is the consequence of data analysis or technological innovation. Data has great value; the digital environment allows us to record every action automatically and permanently, and consequently enormous amounts of information are generated. In this context, the SCC should ensure the reliability of the information it handles. On the other hand, the organization needs to ensure its ability to establish key indicators to analyze operational results, financial results, customer satisfaction results, and social results and can have an adequate an efficient management vision and control. In addition to this, it is important that the company makes sure robust data capturing systems are established in addition to defining key indicators suitable. All this is managed with tools according to their size and particular needs.

Once the SCC has the appropriate information systems, it should analyze the data and assess whether the results are aligned with the defined strategy, and from there, establish appropriate action plans. On the other hand, this data analysis should also allow models and predictions to be made that allow for more information about the future to be had.

After examining the data and defining the action plans according to the strategic guidelines, the analysis of non-financial indicators must also be taken into account; that is, the organization needs to carry out an analysis of the environment with a frequency appropriate to its size and activity, allowing for the needs of stakeholders to be continually reviewed, changes in market players to be possibly made, and for technological innovations and other changes in the environment that may affect an organization. 
Finally, the organization needs to base part of its strength on encouraging continuous improvement from within, creating a mindset for creativity and innovation, including disruptive thinking as an essential ingredient in helping an organization generate increased value and an improved level of performance. The cyclical relations between the elements described before are shown below (see Figure 4).

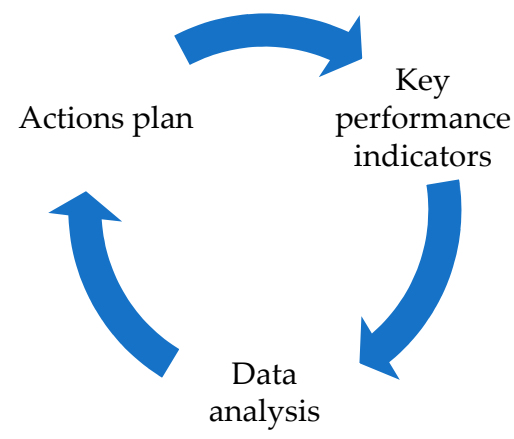

Figure 4. Subcategories in continuous improvement dimension.

The quality model for social collaborative companies is represented in the Figure 5.

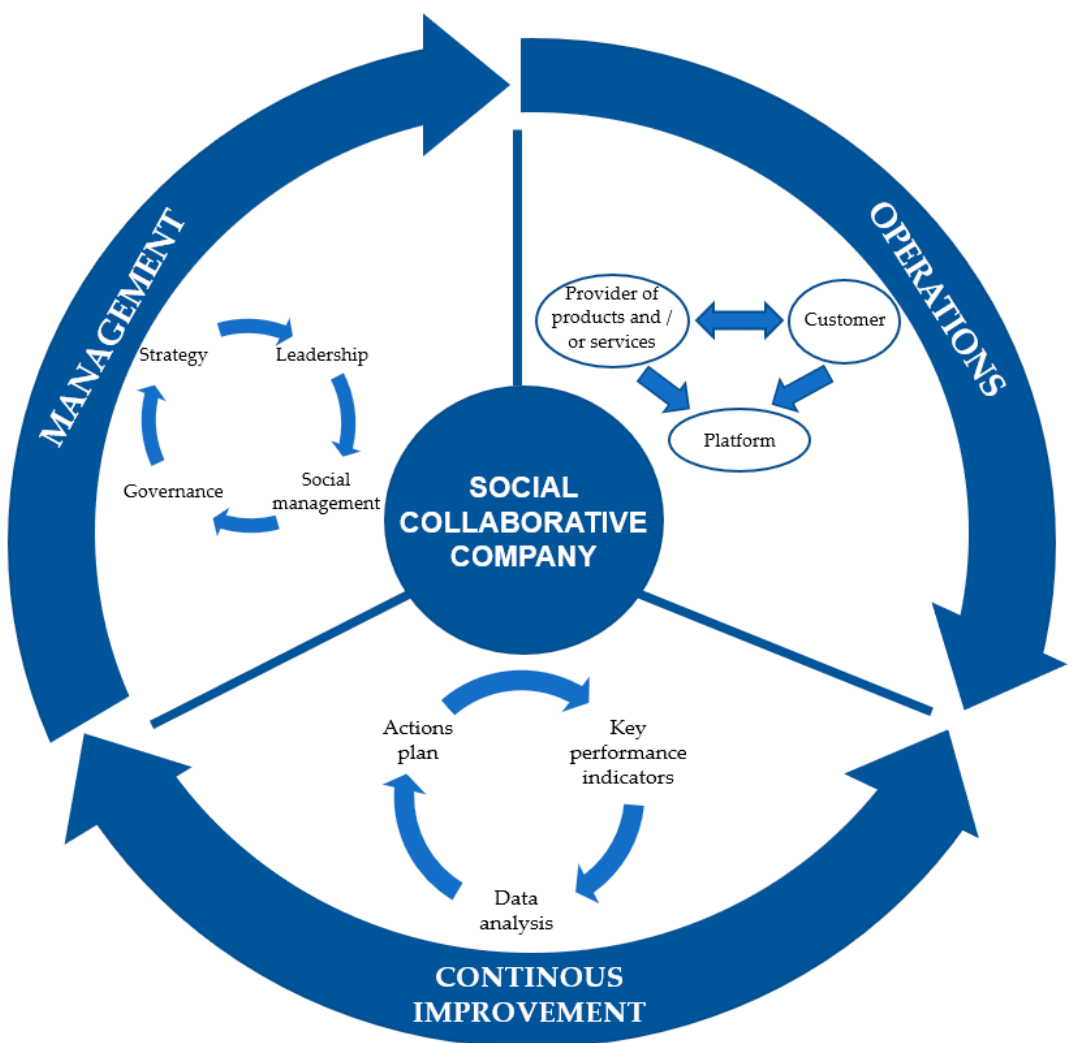

Figure 5. Quality model for social collaborative companies.

After this detailed literature review and development of the quality model for social collaborative companies, we have now reached the stage where we need some independent feedback as to how well our model meets our objectives. We perform this validation through involving a group of five experts (practitioners and academics) in examining our quality model components and completing a detailed questionnaire (see Appendix A). A major part of this expert feedback is devoted to explaining the validation of the proposed model. 
All the expert analysis and feedback of the model suggested similar viewpoints with some individual and important contributions. All the experts agreed that is not necessary to add one on more dimensions (management, operation, and continuous improvement) to the quality model, and that there is no key missing point in any dimension proposed. However, they have made comments and questions that were an appreciated input for the development of the model in each of these aspects.

About the management dimension, Expert 2 asked: "Does governance include management control?" To answer this, we considered that it was important to include the control management in this dimension; for the other side, Expert 5 recommended considering a Leadership dimension separately if the SCCs ask for it.

Regarding the operations dimension, Expert 4 suggests: "I would be explicit in what type of contracts, agreements, term and conditions apply to each link". With this comment, we are aware that this legal aspect is out of the quality model scope, because it is in the scope of this field of research, but the quality model offers the guideline of how these relations need to work for the SCC to deliver products or services in good quality conditions.

About the continuous improvement dimension, Expert 1 stated: "I am not sure if the society is represented in the model (not only the customer, but also society as participant and beneficiary)". For this reason, we added in the proposed SCC definition that these types of companies must have a social mission, a positive impact in society. Expert 2 stated: "Control seem to be missing"; to answer this, we highlighted that the information received from of the data is necessary for an adequate decision and control management. Furthermore, Expert 3 stated: "Why not a PDCA model?" We include the Quality service model for collaborative companies in the literature review, including the PDCA model. Finally, Expert 4 recommended: "In future, you also need to look at disruptive tech or management ideas that could have impact on your company (SCC companies), even in other sectors". This is a very important comment for future research. Expert 4 added: "I would just add data somewhere as the source for this continuous loop". Regarding this comment, we highlight the use of data, like a source of information to business decisions towards a better performance.

Regarding the overall valuation based on a scale from 1 (not at all) to 5 (absolutely), almost all the experts except for one (who gave 5 points) gave 4 points for the question "it is clear enough to provide an idea of how the model works". Furthermore, all experts gave equal importance to all the three dimensions of the quality model.

Therefore, we conclude that this quality model can be an important tool to help SCCs to know themselves better, and to have a guide for management with focus on delivering product and services at an adequate level of quality. Also, to record the data related with the key point and to develop actions oriented to improvement each time and be inputs for the current and future strategies.

\section{Conclusions, Implications, and Future Research}

Having reviewed the literature on the collaborative economy and the social economy, and having analyzed the points at which they meet, the new concept of a social collaborative company is proposed, which aims to frame companies that have a social mission and a democratic style of governance, whether or not they are cooperatives or operate through a platform in a collaborative environment, taking advantage of the benefits of efficiency and scalability, among others. This concept contributes to the recognition of companies; it is useful, because they can begin to delve into their particularities and develop more knowledge in this field.

The literature review has also included a search for quality models that apply to these types of companies regardless of the product or service they offer to the market, thereby detecting a gap that has been resolved with the proposal of a quality model for social collaborative companies with these objectives: (i) offering a management guide for excellence; (ii) being a tool for benchmarking; and (iii) being a tool for internal and external communication, which was validated by experts. 
The quality model established has three categories (management, operations, and continuous improvement) that aim to provide answers to the most important aspects of management that have an impact on the quality of products or services. In the management category, the focus is on strategy, leadership, the social mission, and the complexity that this type of governance can have; in the operations category, the focus is on operational excellence, considering the platform as a facilitator of the product or service that must be treated simultaneously with the product or service, and finally the category of continuous improvement focuses on the importance of measuring the key aspects of management and making decisions based on objective data, which should constitute input for improvement. This quality model is open and can be combined with other management tools.

This study opens up interesting future avenues for research in the field of social economy and collaborative economy as regards the deepening of the concept of an SCC. On the other hand, the quality model has been based on a literature review and has not yet been validated; therefore, a qualitative or quantitative validation could be valuable research that would provide knowledge that would allow adjustments to the model and that could be improved so it can better serve the purpose for which it was designed.

The quality model presented in this research was designed for an SCC, which is a new concept that has been introduced in this document. To find these companies, it will be necessary to establish compliance criteria and evaluate whether the characteristics that have been initially defined are applicable to real companies. After this, another investigation can be the application of this model to real cases of SCCs and evaluate its effectiveness.

Author Contributions: Conceptualization, P.M.C. and R.M.S.; Methodology, P.M.C., R.M.S. and F.M.; Investigation, P.M.C.; Writing original draft preparation, P.M.C.; Writing review and editing, P.M.C., R.M.S. and F.M.; Supervision, R.M.S. and F.M. All authors have read and agreed to the published version of the manuscript.

Funding: This research was funded by MINISTRY OF SCIENCE, INNOVATION AND UNIVERSITIES OF SPAIN and is part of a research project titled "Improvement of quality in collaborative consumption companies: model, scale and loyalty", grant number RTI2018-096279-B-I00.

Acknowledgments: This article was written as part of a research project titled "Improvement of quality in collaborative consumption companies: model, scale and loyalty (CC-QUAL)" (ref: RTI2018096279-B-I00) financed by the Ministry of Science, Innovation, and Universities of Spain within the aid program for R\&D “Retos Investigación” project.

Conflicts of Interest: The authors declare no conflict of interest.

\section{Appendix A}

Questionnaire from empirical validation of this article: On the convergence of Collaborative and Social Economy: A Quality Model for the combined effects

1. Would you add one or more dimensions in the model showed in Figure 1? Which?

2. Would you drop a dimension in the model showed in Figure 1? Which?

3. Is there any key point missing in the "management" dimension in Figure 2? Which?

4. Is there any key point missing in the "operations" dimension in Figure 3? Which?

5. Is there any key point missing in the "continuous improving" dimension in Figure 4? Which?

6. Is Figure 5 clear enough to provide an idea of how the model works? Say between 1 (not at all) and 5 (absolutely). Distribute 10 points among the three dimensions of the model, according to the importance of each one (management, operations, and continuous improvement).

\section{References}

1. Hamari, J.; Sjöklint, M.; Ukkonen, A. The Sharing Economy: Why people Participate in Collabortive Consumption. J. Am. Soc. Inf. Sci. Technol. 2016, 64, 1852-1863. [CrossRef]

2. Ert, E.; Fleischer, A.; Magen, N. Trust and Reputation in the Sharing Economy: The role of personal photos in Airbnb. Adv. Consum. Res. 2015, 43, 518-519. [CrossRef] 
3. McIntyre, D.P.; Srinivasan, A.; Chintakananda, A. The persistence of platforms: The role of network, platform, and complementor attributes. Long Range Plan. 2020, 101987. [CrossRef]

4. Benoit, S.; Baker, T.L.; Bolton, R.N.; Gruber, T.; Kandampully, J. A triadic framework for collaborative consumption (CC): Motives, activities and resources \& capabilities of actors. J. Bus. Res. 2017, 79, 219-227. [CrossRef]

5. Barnes, S.J.; Mattsson, J. Understanding Current and Future Issues in Collaborative Consumption: A Four-Stage Delphi Study. Technol. Forecast. Soc. Chang. 2016, 104, 200-211. [CrossRef]

6. Muñoz, P.; Cohen, B. A compass for navigating sharing economy business models. Calif Manag. Rev. 2018, 61, 114-147. [CrossRef]

7. Botsman, R.; Rogers, R. What's Mine Is Yours: How Collaborative Consumption Is Changing the Way We Live; Harper Collins: New York, NY, USA, 2010.

8. Ozanne, L.K.; Ozanne, J.L. A child's right to Play: The social construction of civic virtues in toy libraries. J. Public Policy Mark. 2011, 30, 264-278. [CrossRef]

9. Alzamora-Ruiz, J.; Guerrero-Medina, C.; Martínez-Fiestas, M.; Serida-Nishimura, J. Why people participate in collaborative consumption: An exploratory study of motivating factors in a Latin American economy. Sustainability 2020, 12, 1936. [CrossRef]

10. Belk, R. You are what you can access: Sharing and collaborative consumption online. J. Bus. Res. 2014, 67, 1595-1600. [CrossRef]

11. Baden, D.; Peattie, K.; Oke, A. Access over ownership: Case studies of libraries of things. Sustainability 2020, 12, 7180. [CrossRef]

12. Sundararajan, A. The Sharing Economy: The End of Employment and the Rise of Crowd-Based Capitalism; The MIT Press: Cambridge, MA, USA, 2016.

13. Scholz, T. Platform Cooperativism. South Atl. Q. 2019, 118, 801-819. [CrossRef]

14. Wilhelms, M.P.; Henkel, S.; Falk, T. To earn is not enough: A means-end analysis to uncover peer-providers' participation motives in peer-to-peer carsharing. Technol. Forecast. Soc. Chang. 2017, 125, 38-47. [CrossRef]

15. Olsi, J. Practicing Law in the Sharing Economy: Helping People Build Cooperatives, Social Enterprise and Local Sustainable Economies; American Bar Association: Chicago, IL, USA, 2013.

16. Diaz-Foncea, M.; Marcuello, S.C.; Monreal, G.M. Economía Social y Economía Colaborativa: Encaje y Potencialidades. Econ. Ind. 2016, 402, 27-35.

17. Scholz, T. Platform Cooperativism. 2017. Available online: https://www.researchgate.net/publication/321777389 (accessed on 4 February 2021).

18. Newlands, M. The Sharing Economy: Why It Works and How to Join. 2016. Available online: https://www.forbes.com/sites/ mnewlands/2015/07/17/the-sharing-economy-why-it-works-and-how-to-join/\#7ff43f2f58e1 (accessed on 4 February 2021).

19. Stemler, A. The Myth of the Sharing Economy and Its Implications for Regulating Innovation. SSRN Electron. J. 2017. [CrossRef]

20. Fuster Morell, M. Acción colectiva a través de redes online: Comunidades de Creación Online para la construcción de bienes públicos digitales. Redes. Com. Rev. Estud. Para Desarro Soc. Comun. 2011, 229-248. [CrossRef]

21. Falcón-Pérez, C.E.; Fuentes-Perdomo, J. Improving social well-being through platform cooperativism. CIRIEC-Espana Rev. Econ. Publica Soc. Coop. 2019, 161-190. [CrossRef]

22. Gorenflo, N. How Platform Coops Can Beat Death Stars Like Uber to Create a Real Sharing Economy. 2015. Available online: https://www.shareable.net/reversing-the-mississippi-a-tale-of-two-changemakers/ (accessed on 4 February 2021).

23. Spieth, P.; Schneider, S.; Clauß, T.; Eichenberg, D. Value drivers of social businesses: A business model perspective. Long Range Plan. 2019, 52, 427-444. [CrossRef]

24. Zale, K. Sharing Property. Univ. Color Law Rev. 2016, 87, 501-579.

25. Gansky, L. Collaborative Economy Companies Need to Start Sharing More Value with the People Who Make Them Valuable. 2014. Available online: https://www.fastcompany.com/3038476/collaborative-economy-companies-need-to-start-sharingmore-value-with-the-people-who-make-th (accessed on 4 February 2021).

26. Conaty, P.; Bollier, D. Toward an Open Co-Operativism: A New Social Economy Based on Open Platforms, Co-Operative Models and the Commons. Rep. Commons Strateg Gr Work Berlin Ger. 2014. Available online: https://www.boell.de/en (accessed on 4 February 2021).

27. Bauwens, M. Open Cooperativism for the P2P Age. 2014. Available online: https://blog.p2pfoundation.net/open-cooperativismfor-the-p2p-age/2014/06/16 (accessed on 4 February 2021).

28. Stokes, K.; Clarence, E.; Anderson, L.; Rinne, A. Making Sense of the UK Collaborative Economy; Nesta. Collaborative Lab.: London, UK, 2014.

29. Richardson, L. Performing the sharing economy. Geoforum 2015, 67, 121-129. [CrossRef]

30. Mas-Machuca, M.; Ballesteros-Sola, M.; Guerrero, A. Unveiling the mission statements in social enterprises: A comparative content analysis of US- vs. Spanish-based organizations. J. Soc. Entrep. 2017, 8, 186-200. [CrossRef]

31. Bauwens, M.; Iacomella, F.; Mendoza, N.; Burke, J. Synthetic Overview of the Collaborative Economy; P2P Foundation: Amsterdam, The Netherlands, 2005; pp. 1-4.

32. Ertz, M.; Leblanc-Proulx, S. Sustainability in the collaborative economy: A bibliometric analysis reveals emerging interest. J. Clean. Prod. 2018, 196, 1073-1085. [CrossRef]

33. Priporas, C.V.; Stylos, N.; Rahimi, R.; Vedanthachari, L.N. Unraveling the diverse nature of service quality in a sharing economy: A social exchange theory perspective of Airbnb accommodation. Int. J. Contemp. Hosp. Manag. 2017, 29, 2279-2301. [CrossRef]

34. Melão, N.; Bastida, R.; Marimon, F. Assessing a quality model for the social sector: An empirical study of the EQUASS model. Total Qual. Mana. Bus. Excell. 2019, 30, 221-243. [CrossRef] 
35. Marimon, F.; Melão, N.; Bastida, R. Motivations and benefits of quality management systems in social services: Mediation of the implementation process. Total Qual. Manag. Bus. Excell. 2019, 1-26. [CrossRef]

36. Melão, N.; Amorim, M.; Marimon, F.; Alegre, I. Quality management systems in European social service organizations: A survey of EQUASS Assurance pioneer adopters. Int. J. Qual. Reliab. Manag. 2018, 35, 354-372. [CrossRef]

37. EQUASS. EQUASS 2018 Principles, Criteria and Indicators. (Repositori.uic.es). 2018. Available online: http:/ / repositori.uic.es/ bitstream/handle/20.500.12328/1112/Marimon\%20Viadiu,\%20Frederic\%20et\%20al._Assessing\%20a\%20quality\%20model_20 19.pdf;jsessionid=FE69388AF73A45327D5A3A4A9C1A5162? sequence=1 (accessed on 4 February 2021).

38. Parasuraman, A.; Zeithaml, V.; Berry, L. A Conceptual Model of Service Quality and Its Implications for Future Research. J. Mark. 1985, 49, 41-50. [CrossRef]

39. Grönroos, C. The perceived service quality concept-a mistake? Manag. Serv. Qual. Int. J. 2001, 11, 150-152. [CrossRef]

40. Hauber, D.C. A Study of the EFQM Model. Master's Thesis, Universitat de Barcelona, Barcelona, Spain, 5 July 2020. Available online: http://diposit.ub.edu/dspace/bitstream/2445/172128/1/TFM-INTBUS-Hauber_2020.pdf (accessed on 4 February 2021).

41. Shahin, A. Developing the Models of Service Quality Gaps: A Critical Discussion. Bus. Manag. Strateg. 2010, 1, 1-11. [CrossRef]

42. Deming, W.E. The New Economy for Industry; Goverment; Education; The MIT Press Cambridge: Cambridge, MA, USA, 1993.

43. Seth, N.; Deshmukh, S.G.; Vrat, P. Service Quality Models: A Review. Int. J. Qual. Reliab. Manag. 2005. [CrossRef]

44. Yarimoglu, E.K. A Review on Dimensions of Service Quality Models. J. Mark Manag. 2014, 2, 79-93.

45. European Comission. Communication from the Commission to the European Parliament, the European Economic and Social Commitee of the Regions: A European agenda for the collaborative economy. Eur. Comm. 2016, 16. [CrossRef]

46. Kim, B. Understanding Key Antecedents of Consumer Loyalty toward Sharing-Economy Platforms: The Case of Airbnb. Sustainability 2019, 19, 5195. [CrossRef]

47. Markides, C.; Sosa, L. Pioneering and first mover advantages: The importance of business models. Long Range Plan. 2013, 46, 325-334. [CrossRef]

48. Fuster Morell, M. The unethics of sharing: Wikiwashing. Int. Rev. Inf. Ethics. 2011, 15, 9.

49. Pearce, J.; David, F. Corporate Mission Statements: The Bottom Line Corporate Mission Statements: The Bottom Line. Acad. Manag. Perspect. 2015, 1, 109-115. [CrossRef]

50. Hsieh, Y.C.; Hiang, S.T. A Study of the Impacts of Service Quality on Relationship Quality in Search-Experience-Credence Services. Total Qual. Manag. Bus. Excell. 2004, 15, 43-58. [CrossRef]

51. Akhmedova, A.; Marimon, F.; Mas-Machuca, M. Winning strategies for customer loyalty in the sharing economy: A mixedmethods study. J. Bus. Res. 2020, 112, 33-44. [CrossRef] 